\title{
Influence of selected active substances of fungicides and herbicides and time of their application on chlorophyll content in Triticum aestivum L.
}

\author{
Wpływ wybranych substancji czynnych fungicydów, herbicydów \\ i ich terminów aplikacji na poziom barwników asymilacyjnych \\ w Triticum aestivum $\mathrm{L}$.
}

\author{
Bożena Łozowicka ${ }^{1}$, Elżbieta Wołejko ${ }^{2}$, Rafał Konecki ${ }^{1 *}$
}

\begin{abstract}
Summary
The aim of the study was to assess the influence of various combinations of two sets of fungicides and one herbicide in three cultivars of spring wheat (Arabella, Kandela, Struna) on changes in the concentration of total chlorophyll. Based on these results, it was found that chlorophyll increased in the leaves from 5 to 12\%, except for an application of thiophanat methyl and azoxystrobin on the cultivar Struna. The herbicide treatment resulted in a decrease of the chlorophyll content in relation to the control plots on average from 2 to $8 \%$, while the combination of herbicide with fungicides resulted of an increase of the chlorophyll content in three cultivars of wheat. Among the examined wheat cultivars, Struna was the most tolerant to the treatments of fungicides and the herbicide included in research.
\end{abstract}

Key words: chlorophyll; spring wheat; cultivars; fungicide; herbicides

\section{Streszczenie}

Celem prowadzonych badań była ocena zmian zawartości chlorofilu całkowitego pod wpływem różnych kombinacji dwóch zestawów fungicydów i herbicydu w trzech odmianach pszenicy jarej (Arabella, Kandela, Struna). Poziom chlorofilu całkowitego w pszenicy, na którą zaaplikowano fungicydy był wyższy od stężenia barwników roślin z poletek kontrolnych. Zaobserwowano wzrost zawartości chlorofilu od 5 do 12\%, z wyjątkiem aplikacji tiofanatu metylu i azoksystrobiny na odmianę Struna. Zabieg przeprowadzony wyłącznie herbicydem wywołał spadek poziomu chlorofilu w odniesieniu do poletek kontrolnych średnio od 2 do $8 \%$. Połączenie herbicydu z fungicydami spowodowało wzrost stężenia chlorofilu w trzech odmianach pszenicy. Pośród badanych odmian pszenicy najbardziej tolerancyjną odmianą na zastosowane fungicydy i herbicyd była odmiana Struna.

Słowa kluczowe: chlorofil; pszenica jara; odmiany; fungicydy; herbicydy

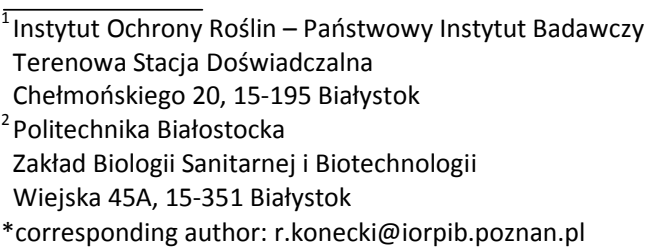




\section{Wstęp / Introduction}

Wielkość plonu roślin zbożowych jest uzależniona w dużym stopniu od sprawnego przebiegu procesu fotosyntezy oraz dystrybucji asymilatów w trakcie trwania sezonu wegetacyjnego, w których kluczową rolę odgrywa zaopatrzenie roślin w makro- i mikroelementy (Starck 2008). Na procesy fizjologiczne zachodzące w roślinach uprawnych znaczny wpływ mogą wywierać środki ochrony roślin (ś.o.r.). Oddziaływanie fungicydów i herbicydów na roślinę uprawną, uzależnione $\mathrm{w}$ dużej mierze od budowy i właściwości substancji czynnej, może prowadzić do zmian strukturalnych lipidów, białek, chlorofilu i kwasów nukleinowych (Kalaji i Rutkowska 2004). Związki te wykazują działanie zarówno systemiczne, wgłębne, jak i powierzchniowe (Stajner i wsp. 2003). Substancje czynne (s.cz.) ś.o.r. wnikając do roślin mogą przyczyniać się do powstawania wysoce toksycznych nadtlenków powodujących między innymi dezorganizację struktur komórkowych, uszkodzenia błon plazmatycznych, a tym samym degradację chlorofilu. Ekmekci i Terzioglu (2005) wskazują, że działanie herbicydów uwarunkowane jest obecnością układu chloroplastów, światła oraz tlenu molekularnego. Szybkie uszkodzenia roślin pod wpływem działania herbicydów są następstwem całkowitej dezorganizacji struktury i funkcji komórek z powodu oddziaływania toksycznych nadtlenków. Niszczą one struktury membranowe, wywołują duże zmiany morfologiczne i ultrastrukturalne oraz powodują szybkie wysychanie (desykację) roślin. Badania Jaing i wsp. (2009) wskazują, iż w takich warunkach może dochodzić również do funkcjonalnych i strukturalnych zmian w aparacie fotosyntetycznym, co w efekcie ogranicza wzrost roślin i ich produktywność.

Chlorofile należą do najpowszechniej występujących barwników w roślinach. Występują one w każdej zielonej części roślin eksponowanych na światło (Aarti i wsp. 2006). W badaniach przeprowadzonych przez Kozłowskiego i wsp. (2001) stwierdzono, iż w liściach roślin zawartość tych barwników wynosi średnio $0,25 \%$. W chloroplastach są one powiązane ze specyficznymi białkami, glikolipidami i sulfolipidami oraz innymi składnikami, co zapewnia stabilizację układu. Do czynników przyspieszających przemiany chlorofili zalicza się: wysoką temperaturę, kwaśne środowisko, enzymy (chlorofilazę, lipooksygenazę i lipazę) oraz tlen i światło, a także ś.o.r. (Chun i wsp. 2002; Dżugan 2006).

Celem prowadzonych badań była ocena zmian zawartości chlorofilu całkowitego pod wpływem różnych kombinacji ś.o.r. $\mathrm{z}$ grupy fungicydów i herbicydów $\mathrm{w}$ trzech odmianach pszenicy jarej (Arabella, Kandela, Struna).

\section{Materiały i metody / Materials and methods}

Doświadczenie polowe przeprowadzono w 2014 roku w województwie podlaskim (5311'45.2"N 2300'40.4"E) metodą bloków losowanych w 4 powtórzeniach. Trzy odmiany pszenicy jarej (Arabella, Kandela, Struna) wysiano w terminie wiosennym (31.03.2014 r.). Nawożenie wykonano przed siewem (28.03.2014 r.) stosując nawóz organiczny $(\mathrm{N}-87,5 \mathrm{~kg} / \mathrm{ha}, \mathrm{P}-133 \mathrm{~kg} / \mathrm{ha}$, sub- stancja organiczna - $1400 \mathrm{~kg} / \mathrm{ha}$ ) oraz w fazie strzelania w źdźbło (BBCH 30) saletrę amonową ( $\mathrm{N}-34 \mathrm{~kg} / \mathrm{ha})$. Wydzielono poletka kontrolne $\left(16 \mathrm{~m}^{2}\right)$ bez chemicznej ochrony i bez ręcznego odchwaszczania oraz poletka, na które aplikowano ś.o.r. za pomocą opryskiwacza plecakowego AP-1/p na sprężone powietrze w pięciu wariantach (tab. 1).

Części nadziemne pszenicy pobrano $\mathrm{z}$ każdej kombinacji w odstępie 3 tygodni (BBCH: 12, 16, 23, 54, 75), od kwietnia do lipca, a następnie określono ich suchą masę przy użyciu wagosuszarki (Radwag) w temperaturze $105^{\circ} \mathrm{C}$. W tych samych terminach $\mathrm{w}$ godzinach popołudniowych dokonano pomiarów zawartości chlorofilu w liściach przy użyciu wykalibrowanego miernika SPAD (Minolta 502, Japonia). Kalibracji dokonano wykorzystując zależność regresyjną między danymi empirycznymi otrzymanymi metodą Bruinsmy (mg chlorofilu/g ś.m.) a jednostkami względnymi SPAD (x) (Bruinsma 1963). Na najmłodszym w pełni rozwiniętym liściu roślin losowo pobranych $\mathrm{z}$ każdego poletka dokonano 30 pomiarów w odległości około $4 \mathrm{~mm}$ od brzegu liścia. Wyniki zawartości suchej masy liści i chlorofilu w liściach opracowano statystycznie w pakiecie STATISTICA v. 12 (Statsoft, Polska).

Ocenę stopnia porażenia chorobami grzybowymi przeprowadzono wizualnie zbierając 25 roślin po przekątnej z każdego poletka.

Dane meteorologiczne pobrano $\mathrm{z}$ automatycznej stacji pogodowej zlokalizowanej $\mathrm{W}$ pobliżu doświadczenia (5311'50.2"N 2300'41.4"E).

\section{Wyniki i dyskusja / Results and discussion}

W doświadczeniu na trzy odmiany pszenicy jarej aplikowano herbicyd (MCPA + dikamba) (H), fungicyd (tiofanat metylu i azoksystrobina) (F1), kombinacje herbicydu (MCPA) i fungicydu (tiofanat metylu i azoksystrobina) $(\mathrm{H}+\mathrm{F} 1)$ oraz kombinacje herbicydu (MCPA) i dwóch fungicydów (propikonazol, cyprokonazol + spiroksamina, tebukonazol i triadimenol) $(\mathrm{H}+\mathrm{F} 2)(\mathrm{tab} .1)$.

Warunki pogodowe w okresie prowadzonego doświadczenia charakteryzowały się niskimi opadami, których suma wynosiła odpowiednio w kwietniu - $25 \mathrm{~mm}$, maju $94 \mathrm{~mm}$, czerwcu - $72 \mathrm{~mm}$ oraz lipcu - $74 \mathrm{~mm}$. Odnotowane sumy opadów były niższe średnio o $38 \%$ w odniesieniu do opadów analogicznego okresu czasu (kwiecień-lipiec) lat ubiegłych (2002-2013). Średnie dobowe temperatury $\mathrm{w}$ kwietniu, maju, czerwcu i lipcu wyniosły odpowiednio $8,14,13$ i $20^{\circ} \mathrm{C}$.

W pracy dokonano oceny wpływu zastosowanych ś.o.r. na suchą masę liści poszczególnych odmian. W wyniku aplikacji herbicydu zawierającego dwie s.cz. - MCPA i dikambę $(\mathrm{H})$, stwierdzono redukcję suchej masy liści pszenicy jarej odmiany Kandela o 19\% i odmiany Struna o $6 \% \mathrm{w}$ porównaniu do roślin z poletek kontrolnych.

$\mathrm{Na}$ poletkach po aplikacji fungicydów (F2) wielkość plonu suchej masy była wyższa w odmianach Kandela i Struna średnio o $4 \%$ w porównaniu do poletek kontrolnych. Z kolei po aplikacji fungicydu zawierającego w swoim składzie dwie s.cz. - tiofanat metylu i azoksystrobinę (F1) wielkość plonu suchej masy liści we 
Tabela 1. Zabiegi ochronne wykonane w uprawie pszenicy jarej

Table 1. Protective treatments made in the cultivation of spring wheat

\begin{tabular}{|c|c|c|c|c|c|}
\hline $\begin{array}{l}\text { Nr obiektu } \\
\text { Treatment no. }\end{array}$ & $\begin{array}{c}\text { Obiekty } \\
\text { doświadczenia } \\
\text { Variants } \\
\text { of the experiment }\end{array}$ & $\begin{array}{l}\text { Substancja czynna (s.cz.) } \\
\text { Active substance (a.s.) }\end{array}$ & $\begin{array}{l}\text { Zawartość } \\
\text { s.cz. } \\
\text { Content a.s. } \\
{[\mathrm{g} / \mathrm{l}]}\end{array}$ & $\begin{array}{c}\text { Dawka } \\
\text { Dose } \\
{[1 / \text { ha }]}\end{array}$ & $\begin{array}{l}\text { Termin } \\
\text { Date } \\
\text { of treatment }\end{array}$ \\
\hline 1 & $\mathrm{~K}$ & - & - & - & - \\
\hline 2 & $\mathrm{H}$ & $\begin{array}{c}\text { MCPA - MCPA } \\
\text { dikamba - dicamba }\end{array}$ & $\begin{array}{c}300 \\
40\end{array}$ & 2 & A \\
\hline \multirow{2}{*}{3} & \multirow{2}{*}{$\mathrm{F} 1$} & tiofanat metylowy - thiophanate-methyl & 500 & 1,4 & $\mathrm{~B}$ \\
\hline & & azoksystrobina - azoxystrobin & 250 & 0,8 & $\mathrm{C}$ \\
\hline \multirow{3}{*}{4} & $\mathrm{H}$ & $\begin{array}{c}\text { MCPA - MCPA } \\
\text { dikamba - dicamba }\end{array}$ & $\begin{array}{c}300 \\
40\end{array}$ & 2 & A \\
\hline & \multirow{2}{*}{ F1 } & tiofanat metylowy - thiophanate-methyl & 500 & 1,4 & $\mathrm{~B}$ \\
\hline & & azoksystrobina - azoxystrobin & 250 & 0,8 & $\mathrm{C}$ \\
\hline \multirow[b]{2}{*}{5} & \multirow[b]{2}{*}{$\mathrm{F} 2$} & $\begin{array}{l}\text { propikonazol - propiconazole } \\
\text { cyprokonazol - cyproconazole }\end{array}$ & $\begin{array}{c}250 \\
80\end{array}$ & 0,5 & $\mathrm{~B}$ \\
\hline & & $\begin{array}{c}\text { spiroksamina - spiroxamine } \\
\text { tebukonazol - tebuconazole } \\
\text { triadimenol - triadimenol }\end{array}$ & $\begin{array}{c}250 \\
167 \\
43 \\
\end{array}$ & 0,6 & $\mathrm{C}$ \\
\hline \multirow{3}{*}{6} & $\mathrm{H}$ & $\begin{array}{c}\mathrm{MCPA} \text { - MCPA } \\
\text { dikamba - dicamba }\end{array}$ & $\begin{array}{c}300 \\
40\end{array}$ & 2 & $\mathrm{~A}$ \\
\hline & \multirow[b]{2}{*}{$\mathrm{F} 2$} & $\begin{array}{l}\text { propikonazol - propiconazole } \\
\text { cyprokonazol - cyproconazole }\end{array}$ & $\begin{array}{c}250 \\
80\end{array}$ & 0,5 & B \\
\hline & & $\begin{array}{l}\text { spiroksamina - spiroxamine } \\
\text { tebukonazol - tebuconazole } \\
\text { triadimenol - triadimenol }\end{array}$ & $\begin{array}{l}250 \\
167 \\
43\end{array}$ & 0,6 & $\mathrm{C}$ \\
\hline
\end{tabular}

$\mathrm{K}$ - kontrola - control; $\mathrm{H}$ - herbicyd - herbicide; F1 - pierwszy zestaw fungicydów - first set of fungicides;

F2 - drugi zestaw fungicydów - second set of fungicides

Termin - Treatment date: A - BBCH 21-23, B - BBCH 56-58, C - BBCH 71-73

wszystkich badanych odmianach pozostawała na zbliżonym poziomie w porównaniu do obiektów kontrolnych. Stwierdzono, że po zastosowaniu fungicydu z herbicydem $(\mathrm{F} 1+\mathrm{H})$ wielkość plonu suchej masy liści uległa redukcji o 5\% u odmiany Arabella, natomiast u odmiany Kandela nastąpił wzrost plonu biomasy o $11 \% \mathrm{w}$ porównaniu z roślinami kontrolnymi (rys. 1).

Największy średni przyrost biomasy pszenicy zanotowano $\mathrm{u}$ odmiany Struna $\left(534 \mathrm{~g} / \mathrm{m}^{2}\right)$ na poletkach $\mathrm{z}$ wykonanym zabiegiem dwoma fungicydami zawierającymi pięć s.cz.: propikonazol, cyprokonazol, spiroksamina, tebukonazol i triadimenol (F2), natomiast najniższy u odmiany Kandela $\left(307 \mathrm{~g} / \mathrm{m}^{2}\right)$ na poletkach $\mathrm{z}$ tą samą kombinacją s.cz. fungicydów i herbicydem $(\mathrm{F} 2+\mathrm{H})$.

Produktywność pszenicy uzależniona jest w dużej mierze od czynników agrotechnicznych, środowiskowych w trakcie ontogenezy, przedplonu, jak również od dystrybucji asymilatów w trakcie rozwoju, które mają wpływ na prawidłowy przebieg fotosyntezy, a tym samym na jakość plonu końcowego (Stajner i wsp. 2003).

W celu stworzenia optymalnych warunków rozwoju pszenicy w trakcie jej wegetacji, prowadzone są chemiczne zabiegi ochronne (Łozowicka i wsp. 2012) przeciw chwastom, takim jak: Chenopodium album L., Capsella bursa-pastoris L., Thlaspi arvense L., czy też Galeopsis terahit L. (Buczek i wsp. 2013) oraz chorobom grzybowym: Rhizoctonia cerealias, Stagonospora nodorum,
Drechslera tritici-repentis i Puccinia recondita (Snarska i Konecki 2013).

Takie zabiegi z jednej strony wpływają na poprawę zdrowotności łanu zmniejszając konkurencyjność wobec chwastów oraz ograniczenie strat plonu ziarna w przypadku porażenia przez patogeny grzybowe (Szumiło i Rachoń 2007), jednak z drugiej strony mogą zakłócać funkcjonowanie komórek poprzez dezorganizację ich struktur, co w konsekwencji może wpłynąć na zmniejszenie gromadzenia biomasy (Jaing i wsp. 2009). Potwierdzają to badania własne, gdzie reakcja poszczególnych odmian na ś.o.r. była bardzo zróżnicowana i zależała od genotypu danej odmiany.

W trakcie wegetacji zaobserwowano wystąpienie chorób grzybowych Pseudocercosporella herpotrichoides, Mycosphaerella graminicola oraz Pyrenophora triticirepentis. Najmniejsze porażenie przez $M$. graminicola (1-5\%) liścia flagowego u odmiany Arabella i Struna zaobserwowano na poletkach, gdzie przeprowadzono zabiegi herbicydem łącznie $\mathrm{z}$ fungicydami $(\mathrm{F} 1+\mathrm{H}$ i F2 + H), a u odmiany Kandela po zabiegu fungicydowym (F1). Nie zaobserwowano istotnych różnic w porażeniu przez M. graminicola liścia podflagowego (12-55\%) poszczególnych odmian i kombinacji. Jednak wystąpienie tej choroby przyczyniło się do spadku zawartości chlorofilu w liściach o $12 \%$ w porównaniu do obiektów kontrolnych, u odmiany Arabella na poletkach, gdzie 

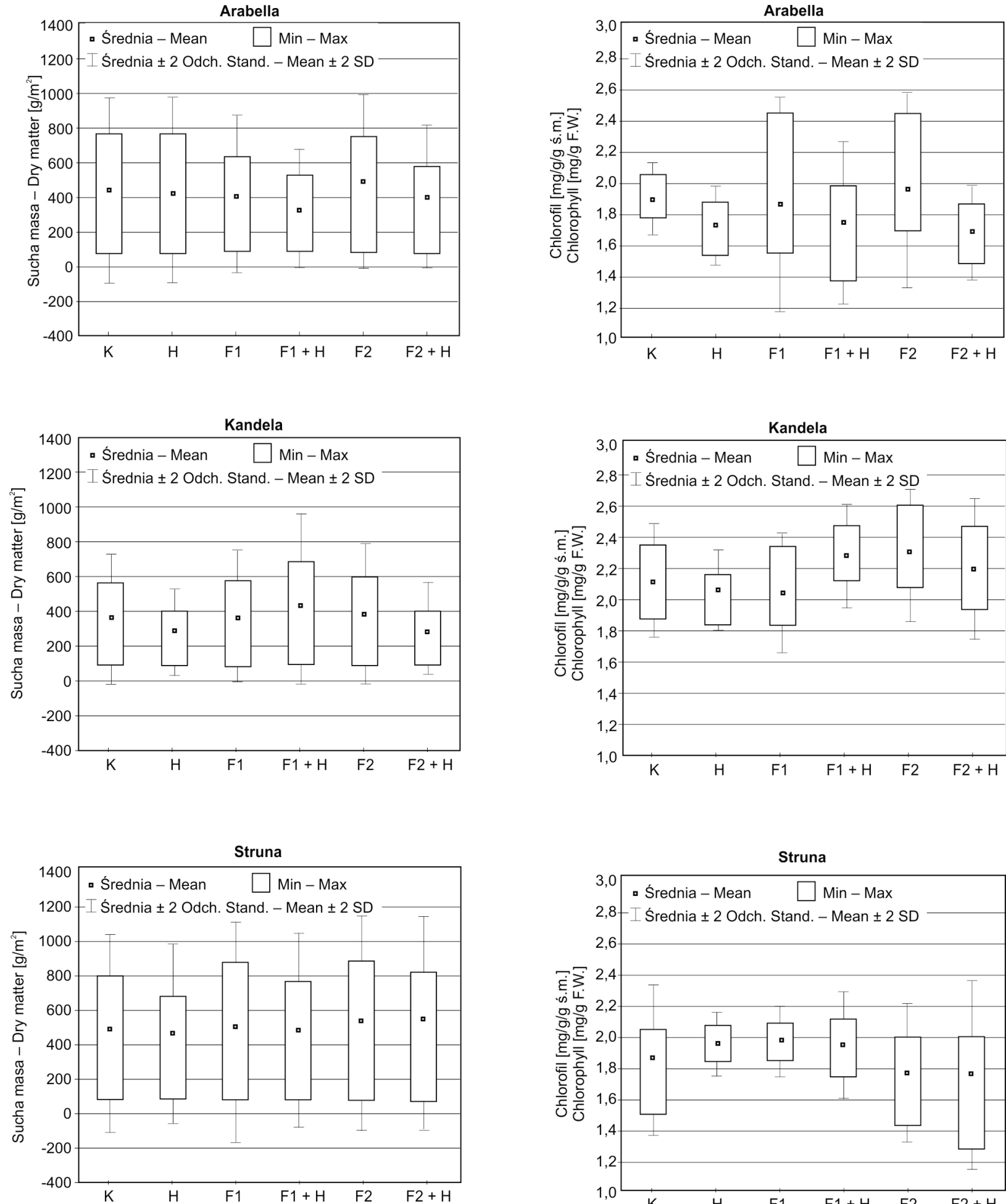

$\mathrm{K}$ - kontrola; $\mathrm{H}$ - herbicyd; F1 i F2 - fungicydy;

$\mathrm{F} 1+\mathrm{H}$ i F2 + $\mathrm{H}-$ kombinacja fungicydów $\mathrm{z}$ herbicydem

$\mathrm{K}$ - control; $\mathrm{H}$ - herbicide; $\mathrm{F} 1$ and $\mathrm{F} 2$ - fungicides

$\mathrm{F} 1+\mathrm{H}$ and $\mathrm{F} 2+\mathrm{H}-$ combinations of fungicides with herbicide

Rys. 1. Wpływ fungicydów i herbicydu oraz ich kombinacji na suchą masę liści trzech odmian pszenicy jarej

Fig. 1. Influence of selected fungicides and herbicide and their combinations on dry matter of leaves of three cultivars of spring wheat

zastosowano herbicyd zawierający w swoim składzie dwie s.cz. - MCPA i dikamba oraz herbicyd łącznie $z$ fungicy-

dami (F1 + H i F2 + H). P. herpotrichoides wystąpiła u odmiany Kandela i Struna $(1-11 \%)$ i nie zaobserwowano 
wpływu tej choroby na zawartość chlorofilu w liściach, natomiast $P$. tritici-repentis wystąpiła $\mathrm{w}$ niewielkim nasileniu w badanych odmianach.

Roślina podczas wegetacji jest narażona na działanie różnych stresów abiotycznych. Starck (2008) wskazuje, że stres ogranicza produkcję fotosyntetyczną nie tylko poprzez degradację chlorofili, ale również narzuca konieczność uruchamiania energochłonnych procesów związanych z aklimatyzacją i adaptacją do niekorzystnych warunków środowiska lub innych czynników egzogennych, takich jak ś.o.r.

W badaniach własnych zastosowana ochrona herbicydowa i fungicydowa spowodowała zmiany w poziomie barwników asymilacyjnych u trzech odmian pszenicy. Poziom chlorofilu w dużym stopniu uzależniony był od zastosowanej odmiany oraz s.cz. herbicydu i fungicydów.

Poziom chlorofilu całkowitego w pszenicy, na którą aplikowano fungicydy był wyższy od poziomu barwników roślin $\mathrm{z}$ poletek kontrolnych. Zaobserwowano wzrost zawartości tego barwnika od 5 do $12 \%$, z wyjątkiem aplikacji tiofanatu metylu i azoksystrobiny (F1) na odmianę Struna. Z kolei zabieg przeprowadzony wyłącznie z wykorzystaniem herbicydu zawierającego w swoim składzie MCPA i dikambę spowodował redukcję zawartości chlorofilu w liściach w odniesieniu do obiektu kontrolnego, średnio od 2 do $8 \%$ u wszystkich trzech badanych odmian pszenicy jarej (rys. 2).

U odmiany Kandela odnotowano najwyższy procentowy wzrost zawartości chlorofilu w liściach pobranych $\mathrm{z}$ obiektu kontrolnego, jak również dla obiektów traktowanych s.cz. herbicydu oraz s.cz. fungicydów. U odmiany Struna zawartość chlorofilu była na zbliżonym poziomie, tj. $2 \mathrm{mg} / \mathrm{g}$ ś.m. Największe zróżnicowanie obserwowano u odmiany Arabella, gdzie zawartość chlorofilu w zależności od zastosowanej ochrony herbicydowej i fungicydowej wahała się w granicach od 1,6 mg/g ś.m. przy F2 + H do $1,9 \mathrm{mg} / \mathrm{g}$ ś.m. przy F2 (rys. 2).

\section{Wnioski / Conclusions}

1. W doświadczeniu odnotowano wpływ herbicydu zawierającego MCPA i dikambę na zmniejszenie suchej masy liści pszenicy jarej, szczególnie u odmiany Kandela.

2. Zastosowanie herbicydu i fungicydów oraz ich kombinacji wpłynęło istotnie na zawartość barwników fotosyntetycznych w liściach trzech odmian pszenicy jarej.

3. Istotne zwiększenie zawartości chlorofilu w blaszkach liściowych zaobserwowano u odmian Arabella i Kandela po aplikacji fungicydu zawierającego tiofanat metylu i azoksystrobinę.

4. Zwiększoną tolerancją na zastosowanie herbicydu na bazie MCPA i dikamby oraz fungicydu zawierającego tiofanat metylu i azoksystrobinę oraz ich kombinacji odznaczała się odmiana Struna.

5. Odmiana Kandela wykazała wysoką tolerancję na zastosowane dwa fungicydy oraz ich kombinacje $\mathrm{z}$ herbicydem.

\section{Podziękowanie / Acknowledgements}

Autorzy pracy dziękują mgr inż. Krystynie Snarskiej za pomoc techniczną $\mathrm{w}$ założeniu doświadczenia oraz poborze próbek do badań.

\section{Literatura / References}

Aarti P.D., Tanaka R., Tanaka A. 2006. Effects of oxidative stress on chlorophyll biosynthesis in cucumber (Cucumis sativus) cotyledons. Physiologia Plantarum 128 (1): 186-197.

Bruinsma J. 1963. The quantitative analysis of chlorophylls A and B in plant extracts. Photochemistry and Photobiology 2: 241-249.

Buczek J., Jarecki W., Bobrecka-Jamro D. 2013. Skuteczność metod regulacji zachwaszczenia w pszenicy jarej. [Efficacy of weed control methods in spring wheat]. Progress in Plant Protection/Postępy w Ochronie Roślin 53 (2): 265-270.

Chun J.C., Kim J.C., Hwang I.T., Kim S.E. 2002. Acteoside from Rehmannia glutinosa nullifies paraquat activity in Cucumis sativus. Pesticide Biochemistry and Physiology 72 (3): 153-159.

Dżugan M. 2006. Czynniki wpływające na stabilność zielonych barwników roślin. Zeszyty Naukowe Polskiego Towarzystwa Gleboznawczego. Oddział w Rzeszowie 7: 27-33.

Ekmekci Y., Terzioglu S. 2005. Effects of oxidative stress induced by paraquat on wild and cultivated wheats. Pesticide Biochemistry and Physiology 83 (2-3): 69-81.

Jaing Q., Zhang J.Y., Guo X., Monteros M.J., Wang Z.Y. 2009. Physiological characterization of transgenic alfalfa (Medicago sativa) plants for improved drought tolerance. International Journal of Plant Sciences 170 (8): 969-978.

Kalaji H.M., Rutkowska A. 2004. Reakcje aparatu fotosyntetycznego siewek kukurydzy na stres solny. Zeszyty Problemowe Postępów Nauk Rolniczych 496: 545-558.

Kozłowski S., Goliński P., Golińska B. 2001. Barwniki chlorofilowe, jako wskaźniki wartości użytkowej gatunków i odmian traw. Zeszyty Problemowe Postępów Nauk Rolniczych 474: 215-223.

Łozowicka B., Miciński J., Zwierzchowski G., Kowalski I.M., Szafarek J. 2012. Cereal grain and feed material containing residues of plant protection chemicals and their effects on human and animal health. Polish Journal of Environmental Studies 21: 181-190.

Snarska K., Konecki R. 2013. Występowanie chorób grzybowych i ich wpływ na wysokość plonu pszenicy w Polsce północno-wschodniej. [Occurrence of fungal diseases and their impact on the quality and amount of wheat grain yield in north-eastern Poland]. Progress in Plant Protection/Postępy w Ochronie Roślin 53 (2): 364-367.

Stajner D., Popovic M., Stajner M. 2003. Herbicide induced oxidative stress in lettuce, beans, pea seeds and leaves. Biologia Plantarum 47 (4): $575-579$.

Starck Z. 2008. Stresy wynikające z nieprawidłowego odżywiania roślin azotem. [Stresses provoked by incorrect nitrogen nutrition in plants]. Postępy Nauk Rolniczych 60 (1): 27-42.

Szumiło G., Rachoń L. 2007. Siewy czyste i mieszane nagoziarnistych i oplewionych odmian jęczmienia jarego i owsa. Zeszyty Problemowe Postępów Nauk Rolniczych 516: 257-265. 